\title{
The identification and management of water losses in water systems by computer analysis
}

\author{
G. Perillo \& F. Sorrentino \\ Department of Technology, Naples Parthenope University, Italy
}

\begin{abstract}
A water distribution system requires constant and thorough maintenance in addition to well-organised running procedures. Once built, it must be considered susceptible to malfunctions and therefore in need of continual supervision. Neglecting a water distribution network is a grave error which may result in the total deterioration of the entire system.

First and foremost, a water distribution system requires the monitoring of leaks. There is no such thing as a leak-free water network and such losses are always of some importance even in the best maintained systems.

In order to determine the entity of leaks it is necessary to conduct accurate water measurements at source, at entry to tanks and at entry to the distribution system, and then compare these flows to one another and to the readings taken at the individual distribution meters. This paper aims to analyse the process for identifying and monitoring leaks in water systems with particular reference to the use of computerised systems which, once in place, can undertake the continuous number-crunching task of comparing the water flows.

'Intelligent' water distribution calls for an integrated system of products, solutions and processes which afford managers the continual remote monitoring and identification of any critical situations; this will enable them to define priorities and establish maintenance interventions and will provide them with the data needed to optimise the performance of the water distribution network.

A survey conducted around the world has shown that intelligent water systems can help distribution companies save up to 12.5 billion dollars per year.
\end{abstract}

Keywords: water losses, computerized systems, management of water. 


\section{Introduction}

This paper aims to discuss an innovative computerised system for the management and monitoring of water distribution systems. Every water system is susceptible to leakages and malfunctions and it is, therefore, critically important to ensure thorough and ongoing maintenance and management procedures.

Losses in water distribution systems are a serious economic and environmental problem. Not only do they represent a waste of precious natural resources but they also incur costs for the system management company [1]. The latter aims to operate the water system while balancing revenues from water sales with maintenance and running costs, expenses for materials and staff, taxes and so on. Losses may also be incurred by small quantities of water not measured by domestic meters [2]. Water used in public services may also represent losses (the watering of public gardens from roadside hydrants, sewer cleaning, etc.) as these can be measured only approximately.

Once an excessive water loss has been determined, it must be located. Water leakage in pressurised systems is a well-known phenomenon, thanks partly to analysis methods based on flow measurements conducted on sections of the network. These methods were introduced in the United Kingdom around 1980 and entailed the division of the distribution system into specific areas by installing valves and flow meters. This technique, known as sectorising or district metering, makes it possible to achieve a sufficiently accurate quantification and identification of system losses.

In general, leaks are thought to make up about $70 \%$ of overall losses and the majority of efforts are directed towards reducing these. However, from a purely economic viewpoint it is impractical to think of reducing leaks beyond a 'physiological' threshold, which experience suggests is between $5 \%$ and $10 \%$ of the overall system volume.

The identification of leaks in pressurised systems has now become a necessity. The growing awareness that water is a precious but finite commodity has resulted in a worldwide commitment to the development of leak detection technologies, which can be classified on the basis of different criteria. One classification in widespread use distinguishes between internal and external leak detection [3, 4]. The former includes those techniques that analyse the characteristics of the water flowing in the pipe, such as pressure and mass balance analysis associated with models simulating fluid motion in permanent non-stationary regime. Whereas external leak detection methodologies envisage the use of a sensor placed on the pipe rather than in the fluid flow. Nowadays we generally use the terms 'softwarebased' and 'hardware based' for the former and latter leak detection methodologies, respectively. 


\section{Materials and methods}

\subsection{Methods}

A water network is driven by consumption. An important category of consumption is water loss, which is defined as the difference between the water entering the network and the water consumed [5-7]. It is therefore necessary to study the network in order to determine which area (or district) has the highest losses.

One of the first activities entails collecting all the available data on the water network. In particular [8]:

- processed data on network water supplies (sources, flow rate, pressure, etc.);

- layouts of the main pipes in the distribution network, the type of material used in their manufacture and their diameters;

- user consumption data or, if unavailable (or of poor quality), data on the area's inhabitants in order to estimate consumption.

Updated maps of the area will then be needed so that all measurements and any other relevant information can be reported on them in order to enable a thorough understanding of the water network - an indispensable requirement if the available data (users, flows, pressure, consumption, etc.) is to be suitably processed. It will then be necessary to identify and locate all the key features, such as pipe intersections, critical users, outlets, etc.

Network analysis is an indispensable tool for collecting data and information so that a mathematical model can be built for simulating network behaviour: this will provide a clear picture of the operations that have to be carried out in order to minimise inefficiency. The mathematical model must reflect the actual situation as far as possible if it is to help optimise the water system and enable its subdivision into single districts. The aim is to create a branching structure in which the exact pipes the water flows along can be identified and the individual areas, residential blocks and end users can be monitored. The task of district management is to subdivide the distribution network into more manageable areas or sectors, within which flows can be measured to determine any leaks present in the system [9].

Water loss is quantified area by area and is assigned to the model according to the length of the pipe associated to every node in the model. In order to ensure that the results provided by the model are trustworthy, their accuracy must be determined by monitoring the flow and the pressure in the network during field tests. The instrumentation used in monitoring includes:

- flow meters (typically Quadrina insertion flow meters, portable ultrasonic flow meters, electromagnetic insertion flow meters);

- pressure transducers;

- data loggers for storing data.

During a field test it is essential to have numerous instruments available in order to be able to record all the points in an area at the same time. This will ensure coherent and comparable data. 


\subsection{Case study}

For our case study we have examined the water network in Spiniello di Acerra (Naples province), which the municipality entrusted to Acquedotti s.c.p.a. in 2006. Over the first three years, the water volumes used were significantly reduced as a result of the monitoring activities conducted in large residential areas (maintenance of water tanks, etc.) and leak repairs. Nevertheless, there was an overall increase in used volumes which, while small thanks to the installation of a night-time regulation system, gradually generated a huge difference between purchased volumes and invoiced volumes. The company therefore decided to carry out a number of interventions to ensure the progressive balancing of water consumption throughout the municipality, which called for a more accurate and more precise system for managing the internal distribution network.

Thus the Spiniello area was analysed by dividing it into 9 water districts covering 1500 end-users overall.

Interventions in the analysed area entailed:

- improvement of the pressure regulator (Clayton) at the regional source (Acqua Campania meter);

- division of the water network into sub-areas by installing 8 line meters and monitoring daily consumption;

- thorough leak detection activities;

- installation of 77 residential area meters, for each building/complex and weekly readings.

Dividing the area into different zones made it easier to identify those network sections with anomalous water consumption. Continuing with the direct identification of consumption by subdividing the Spiniello district into sub-zones pointed out that water consumption was not being measured for a certain percentage of users. The alternative was to fit centralised meters in the various residential complexes in order to facilitate a good approximation of consumption [10].

Having these values constantly available makes it possible to identify any leakage and distribution anomalies. This was achieved by fitting an Itròn EverBlu radio-frequency reading system, providing system managers with fully automated and accurate readings as well as detailed information on consumption, which also helps to process any complaints. The Itròn Everblu system comprises hardware and software to manage the data sent by the meter via its integrated radio module. The EverBlu Collector receives and stores data from its assigned meters on a daily basis and transfers it to the EverBlu Access Point directly or through other Collectors that serve as transmitters. The EverBlu Access Point installed in a central location of each district constitutes the heart of the wireless mesh network. It acquires and stores data from the meters and transmits it to the utility's FTP server on a pre-assigned schedule (typically every day) through a GPRS connection.

In this way Acquedotti s.c.p.a. was able to ensure synchronous remote access to consumption data more frequently than is possible with manual reading [11]. These requirements were justified by economic and operational goals, as an 
operator's hand-held device could remotely acquire data from the meters in a single zone without having to go to each individual meter.

\subsection{Materials}

The Itròn Everblu system comprises hardware and software to manage the data sent by the meter from its integrated radio module. The EverBlu Collector receives and stores data from its assigned meters on a daily basis and transfers it to the EverBlu Access Point directly or through other Collectors that serve as transmitters. The EverBlu Access Point installed in a central location of each district constitutes the heart of the wireless mesh network. It acquires and stores data from the meters and transmits it to the utility's FTP server on a pre-assigned schedule (typically every day) through a GPRS connection.

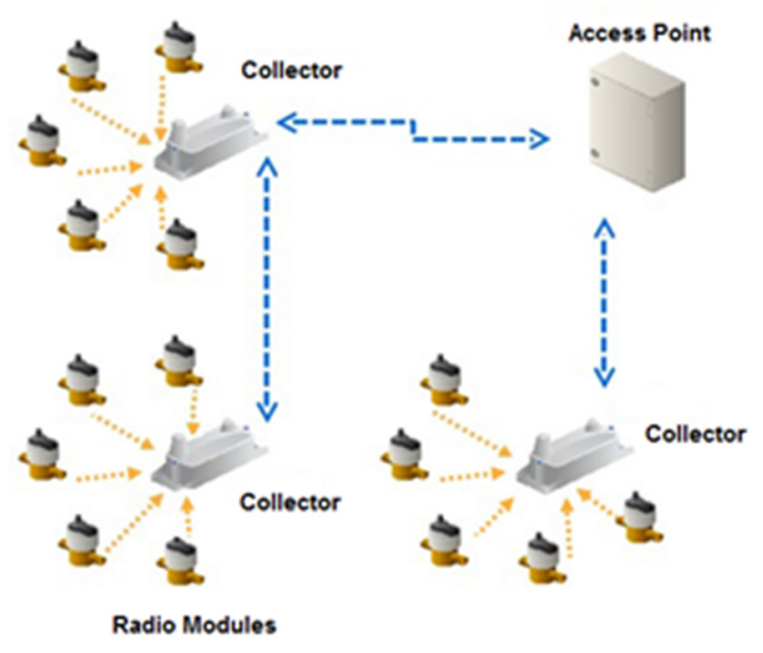

Figure 1: Network architecture with access point, collectors and radio modules.

The EverBlu software drives the data acquisition system from the utility's offices, downloading the daily data from the FTP server to be processed by the operators or exported to application systems. The data is automatically filtered and exported to the invoicing system and to the data centre. Customer service software can be utilised to combine the invoicing and consumption information on the utility's website.

The hardware uses devices such as:

- meter and radio transmitter (Cyble EverBlu);

- first stage transmitters (Collectors);

- data collection equipment (Access point);

- a dedicated management server. 
Software:

- EverBlu Host (Server FTP);

- Everblu.

\subsubsection{The software}

The EverBlu software enables network architecture configuration and maintenance. The list of meters and the network infrastructure can be downloaded directly from the EverBlu Access point, thus avoiding lengthy software set-up processes. When required, installation of a new MIU is extremely straightforward. Operation of the wireless mesh network can be easily monitored through detailed statistical analysis of the radio reading report.

\subsubsection{Data management}

Data is automatically downloaded from the FTP Server daily for analysis by operators or for transfer to the central data base, to the invoicing system or to management applications. EverBlu provides a single instrument for managing automatic meter readings via a hard-wired network or portable terminals.

The EverBlu software provides the operator with graphic analyses of the meter data. Each meter has a consumption curve with zoom, print and data export functions. All additional information (leaks, return flow, alerts, etc.) are displayed by means of simple icons. All the reading data can be easily filtered and exported in a variety of formats. The standard data export format is XML, but other formats (csv, txt, etc.) can be added to facilitate interfacing with any system.

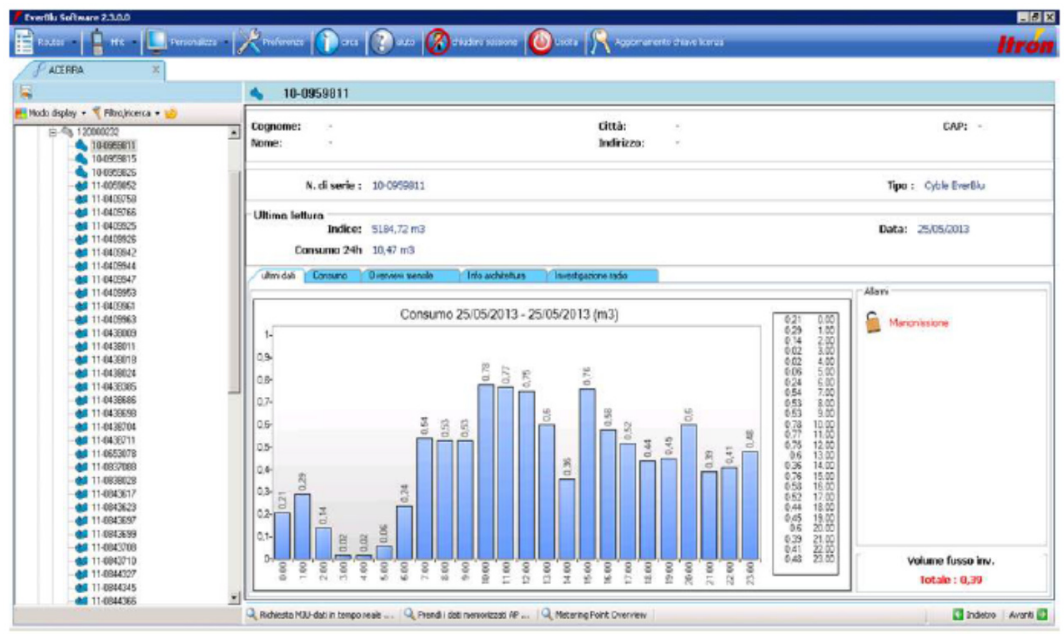

Figure 2: Consumption in a residential complex over 24 hours.

The software imports all the daily data on flows and consumption provided by the Itròn radio modules and organises it by category in the water network's predefined list. 
The program calculates daily water balances for the 9 zones in Spiniello and prepares part of the summary on daily consumption. This gives an immediate overview of the readings and makes it possible for the visualised data to be exported to the database for an aggregate and instantaneous report of flows in the most commonly used formats (such as for Excel and in PDF).

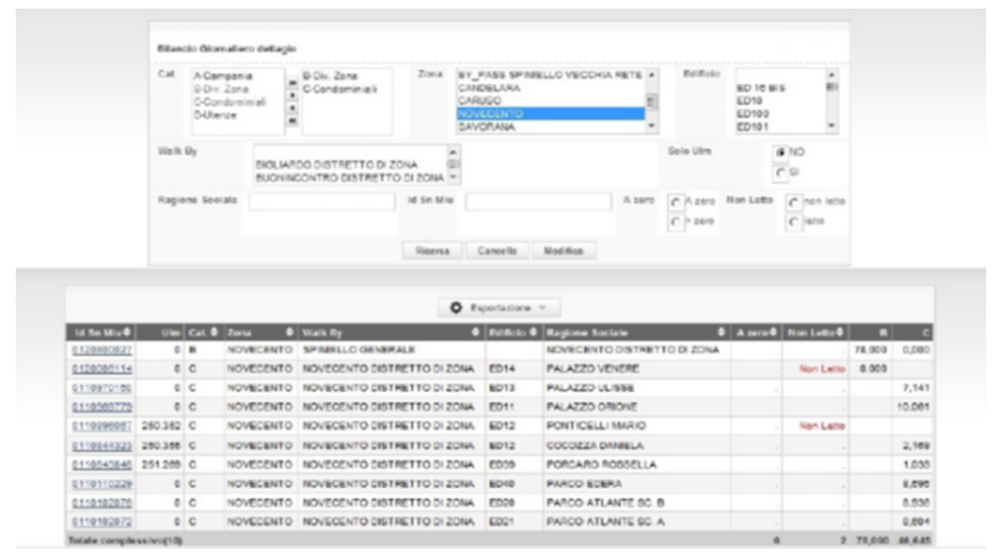

Figure 3: Search for meters and daily consumption.

\section{Conclusions}

The Itròn software generates detailed and analytical data for each meter. This system, installed in the Spiniello di Acerra area, has revealed some technological limits, although it was test-approved and reliable. Acquedotti s.c.p.a. benefitted considerably from using the technology provided by the EverBlu Cyble system; for instance, the data on flows and hourly consumption can be easily stored using the wireless mesh radio system. However, the Everblu software is not continuously updated and any problems detected thanks to the operators' experience and through use of the system over time have to be forwarded to Itròn head office in France, which entails lengthy waiting times both for the management company and for Itròn itself, which deals with thousands of clients. The Itròn system can export data in the formats CSV and XML: the former requires daily intervention by an operator while the latter can connect automatically. Such data can be processed to generate graphs and tables showing consumption but this requires manual selection of each individual meter. Aggregate analyses and reports on daily or weekly consumption cannot be created. If this procedure were extended to all 1500 users for every hour, it would clearly be too laborious. On occasions, operators have had to modify the network mesh on the EverBlu software during routine operation after anomalies were detected in the pipe layouts (for instance, discovering that a single residential complex had several supply points). Indeed, the program does not enable straightforward network mesh management, which turns out to be complex and time-consuming. Another feature that has caused some difficulties was the management of user ID 
data. The system does not allow for swift modifications of the information regarding each user's meter and the procedure takes some time.

In order to overcome the limits of the EverBlu system, the company Alpha Service set up meter management software to support the existing system. The system language is PHP, which enables database management over the Internet using Open Source technology and hence without incurring license charges. The software was designed specifically to be highly customisable and scalable and it also includes a Cloud server which allows data to be stored and processed over the Web.

The program calculates daily water balances and prepares part of the summary on daily consumption. This gives an immediate overview of the readings and makes it possible for the visualised data to be exported to the database for an aggregate and instantaneous report of flows in the most commonly used formats (such as for Excel and in PDF).

This activity can benefit both the manager and the end user as follows:

- benefits for the management and safeguarding of water resources;

- monitoring of network volumes from the regional source;

- monitoring of volumes distributed to each subzone and the related residential complex (building complex meters);

- drafting of the water balance report by comparing collected data;

- alerts on any variation in consumption for an immediate detection of leaks;

- optimisation of the water supply;

- guarantee of error-free traditional meter readings;

- possibility for the user to check individual consumption on the bill or on the website;

_ improved privacy by eliminating frequent interventions at domiciles;

- immediate alert of consumption anomalies (leaks in internal water systems).

This use of computer technology is still in its early stages and ideas for providing a qualitatively and quantitatively better service are coming thick and fast. For instance, there is the possibility for integrating meter readings in municipalities not equipped with the Itròn system: the operator will insert the readings using an ordinary smart phone connected to the Web. Likewise, the geographical location of the radio modules can be identified using Google Maps, and municipalities will be able to monitor water consumption and stocks by entering a reserved area on-line and access individual user information to monitor their water consumption. It will also be possible for the system to send end users (residential complexes and individual consumers) advice on how to save water.

\section{References}

[1] Thorton, J. "Managing leakage by managing pressure". Water 21.3 - IWA Water Loss Task Force, 2003.

[2] Morrison, J. "The management of water loss through the Districts of Measure". Water 21.5 - IWA Water Loss Task Force, 2004. 
[3] Brunone, B. and Ferrante, M. "Detecting leaks in pressurised pipes by means of transients". Journal of Hydraulic Research 39.5, 2001.

[4] "Computational Pipeline Monitoring". American Petroleum Institute, 2002.

[5] Frega, G., "Innovare la gestione dell'acqua in città, rispondere al cambiamento climatico". Lezioni di acquedotti e fognature, Liguori Editore, 2002.

[6] Ippolito, G. "Appunti di Costruzioni Idrauliche". Liguori Editore, 1993.

[7] Brothers, K.J., "A practical approach for the reduction of water losses". Water 21.1 - IWA Water Loss Task Force, 2003.

[8] Fanner, P. "The assessment of actual losses, including the analysis of the components with economic considerations". Water 21.6 - IWA Water Loss Task Force, 2004.

[9] Jönsson, L. "Hydraulic transients as a monitoring device". XXVIII IAHR Congress, Graz, Austria, 1999.

[10] Marzolo, F., Costruzioni Idrauliche. Cedam, 1963.

[11] McKenzie, R. and Lambert, A. "Performance indicators for best practice in estimating the volumes of non-revenue water and the components of loss". Water 21.8 - IWA Water Loss Task Force, 2004. 